\title{
Sı̆̆g Kriyojenik İşlemin Sleipner Soğuk İş Takım Çeliğinin Metalurjik Özellikleri Üzerindeki Etkisinin Araştırılması
}

\author{
Enes EL ${ }^{\mathrm{a}, \mathbb{B}}$, ,Fuat KARA ${ }^{*}, \mathrm{~b}(\mathbb{0})$, Onur ÖZBEK ${ }^{\mathrm{c}}$ (i) \\ ${ }^{a}$ Düzce Üniversitesi, Fen Bilimleri Enstitüsü, Imalat Mühendisliği, 81620, Düzce, Türkiye \\ b,* Düzce Üniversitesi, Mühendislik Fakültesi, Makine Mühendisliği Bölümü, 81620, Düzce, Türkiye \\ ${ }^{c}$ Düzce Üniversitesi, Gümüşova Meslek Yüksekokulu, Makine ve Metal Teknolojileri Bölümü, 81850, Düzce, Türkiye
}

MAKALE ÖZ

BILGISİ

Alınma: 06.04.2021

Kabul: 04.08.2021

\section{Anahtar Kelimeler:}

Sleipner,

Kalintı östenit,

Mikroyap1,

Mikro Sertlik,

Kriyojenik İşlem
Sıfırın altındaki sıcaklıklarda malzemelerin bekletilmesi olarak bilinen kriyojenik işlem, son yıllarda metal ve metal olmayan malzemelerin mekanik özelliklerini iyileştirmek için uygulanan bir yöntemdir. Bu çalıșmada, Sleipner soğuk iș takım çeliği üzerinde sığ kriyojenik işlemin etkilerinin neden olduğu değişimler makro sertlik, mikro sertlik, mikroyapı ve kalıntı östenit hacim oranı yönünden araştırılmıştır. Bu amaçla deney numuneleri önce geleneksel ısıl işlem ile sertleştirilerek 60-62 HRC değerine getirilmiş ardından $-80^{\circ} \mathrm{C}$ sıcaklıkta 18 saat süreyle sı̆̆ kriyojenik işlem uygulanarak, $200{ }^{\circ} \mathrm{C}$ 'de 2 saat boyunca temperleme yapılmıştır. Geleneksel isıl işlem uygulanmış numunenin kalıntı östenit hacim oranı \% 3,6 iken, kriyojenik işlem uygulanmış numunenin oranı \% 1,4 olarak ölçülmüştür. Kalıntı östenit ölçüm sonuçlarına göre östenit hacim oranında yaklaşık \% 61 oranında azalma tespit edilmiștir. Sertlik sonuçlarına göre sığ kriyojenik işlem görmüş numunede makro sertlikte $\% 2$ ve mikro sertlikte $\%$ 7'lik bir artış görülmüş̧ür. Mikroyap1 incelemelerine göre kriyojenik işlem ile daha homojen bir yap1 gözlemlenmiş ve ikincil karbür çökelmeleri görülmüştür.

\section{Researching the Effect of Shallow Cryogenic Treatment on the Metallurgical Features of Sleipner Cold Work Tool Steel}

\section{ARTICLE \\ INFO \\ Received: 06.04.2021 \\ Accepted: 04.08.2021 \\ Keywords: \\ Sleipner, \\ Retained austenite, \\ Microstructure, \\ Micro hardness, \\ Cryogenic treatment}

\begin{abstract}
Cryogenic process, known as holding materials at sub-zero temperatures, is a method applied in recent years to improve the mechanical properties of metal and non-metal materials. In this study, the changes caused by the effects of shallow cryogenic process on Sleipner cold work tool steel were investigated in terms of macro hardness, micro hardness, microstructure and residual austenite volume ratio. For this purpose, the test samples were first hardened by conventional heat treatment and brought to 60-62 HRC value, then by applying shallow cryogenic process at $80^{\circ} \mathrm{C}$ for 18 hours, tempering was performed at $200^{\circ} \mathrm{C}$ for 2 hours. While the residual austenite volume fraction of the conventional heat treated sample was $3.6 \%$, the rate of the cryogenically treated sample was $1.4 \%$. According to the measurement results of retained austenite, it has been determined that the austenite volume decreased by $61 \%$. An increase of $2 \%$ in macro hardness and $7 \%$ in microhardness were observed in the shallow cryogenic processed sample according to the hardness results. According to the microstructure studies, more homogeneous structure was observed with the cryogenic process and secondary carbide precipitation was observed.
\end{abstract}

https://dx.doi.org/10.30855/gmbd.2021.02.04

*Correspondign author: fuatkara@duzce.edu.tr

To cite this article: Özbek, N.A. and Saraç, E. "Effects of Tempering Heat Treatment Temperatures on Mechanical Properties of AISI 1020 and AISI 1040 Carbon Steels," Gazi Journal of Engineering Sciences, vol.7, no.2, pp. 111-120, 2021. doi:https://dx.doi.org/10.30855/gmbd.2021.02.04 


\section{GİRIŞ (INTRODUCTION)}

Teknolojinin günümüzde yüksek bir hızla ilerlemesiyle birlikte farklı malzeme çeşitlerine duyulan ihtiyaçta beraberinde artmıştır. Metallerin mekanik özelliklerinin iyileştirilmesi amacıyla duyulan bu ihtiyaca karşılık olarak özellikle takım çeliklerine uygulanmak üzere çeşitli isıl işlem türleri tercih edilmektedir [1]. Kalıp imalatının büyük çoğunluğunu kapsayan soğuk iş takım çelikleri en yaygın kullanılan takım çeliği grubudur. Sleipner soğuk iş takım çeliği, krom-molibden-vanadyum alaşımı barındıran, yüksek sertlikte olmasına rağmen yüksek tokluğu ile aşınma dayanımında konvansiyonel malzemeler ile karşılaş̧ırıldığında iyi sonuçlar elde etmek mümkün olmaktadır [2]. İcerdiği molibden elementi sayesinde bu çeliklerin akma ve çekme dayanımı yanında, yüksek sıcaklık performansları da artmaktadır [3]. Sleipner soğuk iş takım çeliği, krom-molibden-vanadyum alaşımı barındıran, yüksek sertlikte olmasına rağmen yüksek tokluğu ile aşınma dayanımında konvansiyonel malzemeler ile karşılaştırıldığında iyi sonuçlar sergileyen yeni nesil takım çeliklerinden biridir. Sleipner soğuk iş takım çeliği, vakum ortamında sertleşebilmekle birlikte yüksek sertlik değerlerine çıkabilen, yüksek alaşımlı oldukça iyi toklukla birlikte yüksek aşınma direncine ve kesme yeteneğine sahip, kolay ısıl işlem yapılabilen, isıl işlem esnasında orta derecede boyutsal kararlılık gösteren, kopmama ve dayanma gücüne sahip bir çeliktir. Bu çelikler aşınma dayanımı yüksek DIN 1.2379 çeliğine alternatif olarak geliştirilmiş ve ekstrüzyon, zımbalar, baskı plakaları, madeni eşya, yüksek aşınma direnci gerektiren plastik kalıpların imalatında kullanılmaktadır.

Son yıllarda özellikle takım çeliklerinin mekanik özelliklerini iyileştirmek için 1sıl işlemi tamamlayıcı bir yöntem olan kriyojenik işlem yaygın bir şekilde uygulanmaktadır. Isıl işlem sonrası malzemeye uygulanan kriyojenik işlemin aşınma direnci, sertlik, darbe direnci, çekme dayanımı, yorulma direnci, mikroyapı, kalıntı gerilme ve kalıntı östenit gibi birçok metalürjik özelliği önemli ölçüde iyileştirdiği literatürde belirtilmektedir [4]-[8]. Kriyojenik işlem sı ̆ ve derin olmak üzere ikiye ayrılmış olup, $-50^{\circ} \mathrm{C}$ ve $-100{ }^{\circ} \mathrm{C}$ aralığına sığ kriyojenik işlem, $-125^{\circ} \mathrm{C}$ ve $-196{ }^{\circ} \mathrm{C}$ de uygulanan yönteme ise derin kriyojenik işlem adı verilmektedir [9]-[14]. Geleneksel işleme yöntemleriyle sert malzemelerin işlenmesi söz konusu olduğunda, takım aşınması ve işleme zamanı verimli olmadığı gibi ekonomikte olmamaktadır [15]. Kriyojenik işlem takım ömrünün iyileştirilmesi, verimlilikte artış, kalıntı gerilmelerin azaltılması gibi sebeplerle kullanılmaktadır. Bir sefer yapılan ve etkisi kalıcı olan kriyojenik işlemin, aşınma ve darbe etkilerine maruz bırakılan takım çeliklerinin performansını artırmasının yanı sıra ekonomik bir yöntem olması da bu yöntemi tercih sebebi yapmaktadır [14], [16].

Kriyojenik işlem üzerine literatür araştırılması yapıldığında, K. Amini vd. (2012) AISI D3 soğuk iş takım çeliğinin farklı 1 sıl işlem prosesleri altında aşınma dayanımı ve mikroyapısı incelenmiştir. Numunelere uygulanan östenitleme işleminin akabinde farklı şekillerde soğutularak sertleştirilmiştir. Ardından numunelerin tamamına derin kriyojenik işlem uygulanmış ve temperleme yapılmış̧ır. Deneysel sonuçlarda, isıl işlem zorluğunun artmasıyla birlikte kalıntı östenit miktarında azalmayla birlikte daha homojen karbür dağılımı ve karbür yüzdesinde artış olduğu gözlemlenmiştir. Mikro yapıları incelendiğinde daha homojen ve daha ince karbür dağılımı sıvı nitrojen içerisinde soğutularak sertleştirilen numunede görülse de aşınma direnci ve sertlik bakımından etanol içerisinde soğutularak sertleştirilen numunede en yüksek değerler elde edilmiştir [17]. Kriyojenik işlem uygulamasının temperlenmiş AISI M2, AISI D2 ve $\mathrm{X} 105 \mathrm{CrCoMo} 18$ çelikleri üzerindeki mikroyapı ve mekanik özelliklerine olan etkileri araştırılmıştır. Çalışmanın sonucuna göre, üç çelik türü de temperleme sonrası kriyojenik işlemin sertlik ve elastisite modülü değerlerinde değişiklik göstermediği görülmüştür. Diğer yandan da kriyojenik işlem numuneler üzerindeki kalıntı gidermeleri azaltmakla birlikte kırılma tokluğunu artııılmıştır. Ayrıca mikroyapısında ince homojen dağılmış ikincil karbürlerin çökelmesini de sağlanmıştır [18]. 80CrMo12 5 soğuk iş takım çeliği üzerinde yapılan araştırmada kriyojenik işlemin aşınma davranışına olan etkileri incelenmiştir. $80^{\circ} \mathrm{C}^{\prime}$ de sı̆ $\mathrm{g}$ kriyojenik işlem ve $-196^{\circ} \mathrm{C}^{\prime}$ de derin kriyojenik işlem olmak üzere iki farklı sıcaklıkta kriyojenik işlem sıcaklığı kullanılmıştır. Parametre olarak altı farklı bekletme süresi belirlenmiştir. Deneysel sonuçlara göre, derin kriyojenik işlemin geleneksel 1sıl işlem yöntemine göre aşınma yönünden \% 37-52 oranında iyileşme gösterdiği görülmüştür. Hem sığ hem derin kriyojenik işlem uygulamasının sertlik yönünden sırasıyla yaklaşık olarak \% 1 ile \% 5 iyileşme sağladığı tespit edilmiştir [19].

Literatürde yapılan çalışmalara bakıldığında kriyojenik işlem uygulamalarının olumlu sonuçlar verdiği görülmüştür. Fakat kriyojenik işlemin Sleipner soğuk iş taktım çeliğinin üzerindeki mekanik özelliklerine etkilerini araştıran herhangi bir çalışma bulunamamıştır. Bu çalışmada kriyojenik işlemin Sleipner soğuk iş takım çeliği üzerindeki makro sertlik, mikro sertlik ve kalıntı östenit oranları incelenerek, malzemenin mekanik özelliklerindeki değişimler araştırılmıştır. 


\section{MATERYAL VE METOT (MATERIAL AND METHOD)}

$\mathrm{Bu}$ çalışmada, Sleipner soğuk iş takım çeliği CNC torna tezgahında işlendikten sonra numunelerin tamamına geleneksel isıl işlem yöntemleri uygulanarak 60-62 HRC sertliğe çıkarılmıştır. Kriyojenik işlem öncesi uygulanan 1sıl işlemler Şekil 1'de gösterilmiştir. Ardından araştırmanın gerekliliği olan numuneye sı̆̆ kriyojenik işlem uygulanmış ve akabinde temperleme yapılmıştır. Uygulanan sığ kriyojenik işlem ve temperleme işlemi Şekil 2'de grafiksel olarak gösterilmiştir. Sleipner soğuk iş takım çeliğinin kimyasal bileşenleri Tablo 1'de gösterilmiştir. Kriyojenik işlem Şekil 3'te gösterilen MMD Criyo 125 marka kriyojenik işlem cihazı ile yapılmış olup bu cihaza ait teknik özellikler ise Tablo 2'de yer almaktadır.

Tablo 1. Sleipner çeliğinin kimyasal bileşenleri (\%) (Chemical components of Sleipner steel (\%))

\begin{tabular}{cccccc}
\hline $\mathrm{C}$ & $\mathrm{Si}$ & $\mathrm{Mn}$ & $\mathrm{Cr}$ & Mo & $\mathrm{V}$ \\
\hline 0.90 & 0.90 & 0.50 & 7.8 & 2.5 & 0.50 \\
\hline
\end{tabular}

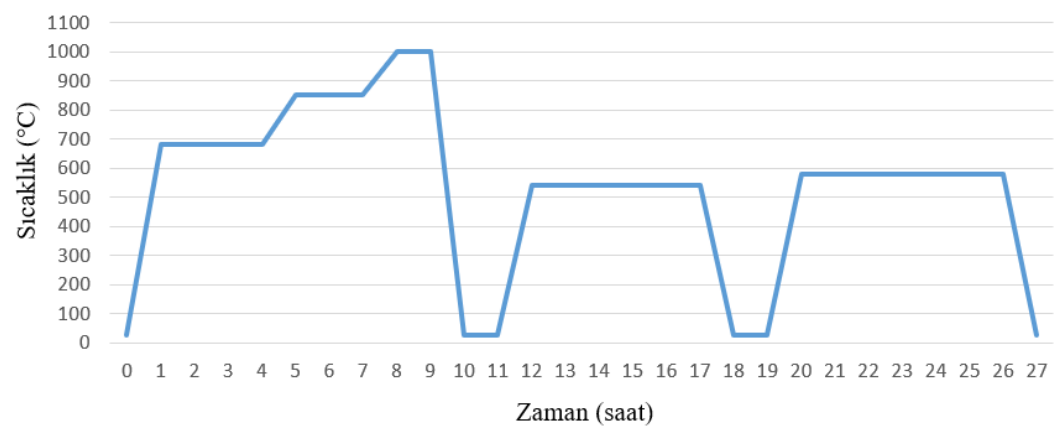

Şekil 1. Kriyojenik işlem öncesi uygulanan 1 sıl işlem grafiği (Chart of heat treatment applied before cryogenic treatment)

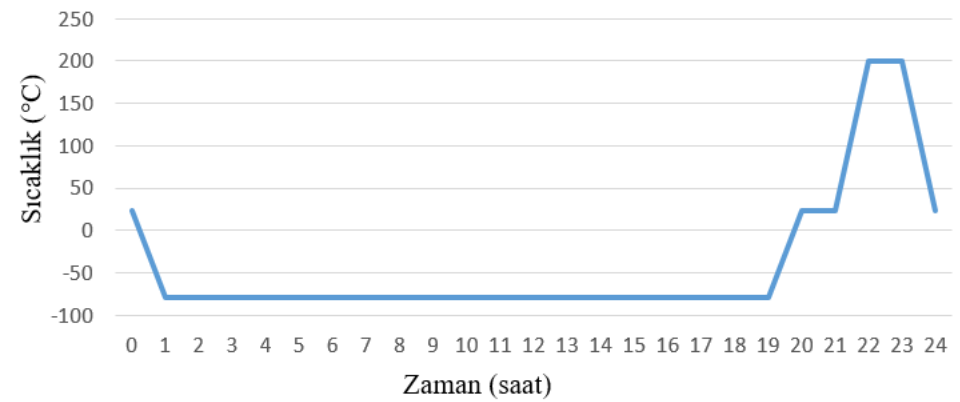

Şekil 2. Sığ kriyojenik işlem ve temperleme işlemi eğrisi (Shallow cryogenic treatment and tempering treatment curve)

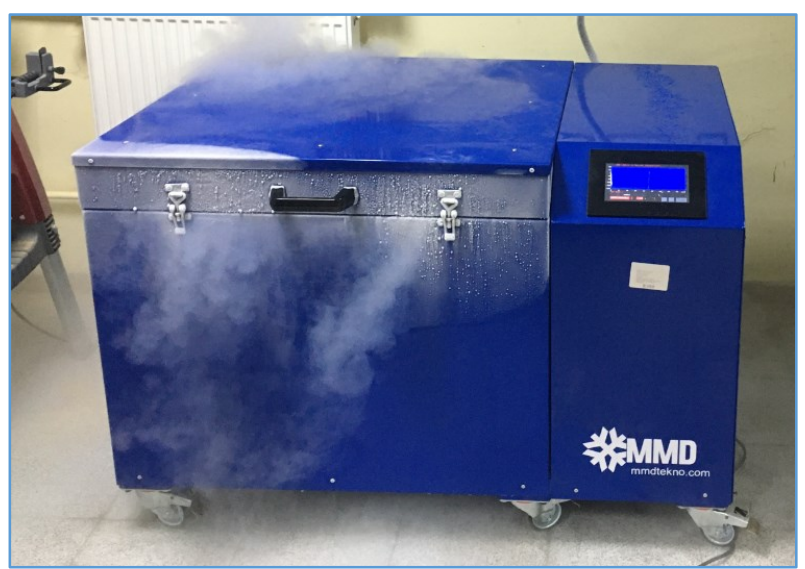

Şekil 3. Kriyojenik işlem cihazı (Cryogenic treatment device) 
Tablo 2. Kriyojenik işlem cihazının teknik özellikleri (Technical specifications of the cryogenic process device)

\begin{tabular}{ll}
\hline İç ölçüler & $60 \mathrm{~cm} \mathrm{Lx} 50 \mathrm{~cm} \mathrm{~W} \mathrm{x} 50 \mathrm{~cm} \mathrm{D}$ \\
İç hazne & 304 paslanmaz çelik \\
Yalıtım & $15 \mathrm{~cm}$ çok katmanlı yalıtım \\
Kapasite & $<100 \mathrm{~kg}$ \\
Kontrol & Dokunmatik ekranlı programlanabilir PLC kontrol \\
Sicaklık sensörü & PT100 \\
LN2 kaynağı & Orta veya yüksek basınçlı sıvı azot kapları ile kullanılabilir \\
LN2 Transfer Bağlantısı & $180 \mathrm{~cm}$ esnek, yalıtımlı kriyojenik sıv1 transfer hortumu \\
LN2 Dozajlama & Selenoid valf \\
İşlem Sicaklığı & $<-190{ }^{\circ} \mathrm{C}$ \\
Sicaklık dağ1lımı & $\pm 2{ }^{\circ} \mathrm{C}$ \\
Soğutma-Isıtma Hızı & $\geq 10^{\circ} \mathrm{C} / \mathrm{dk}$ (malzeme yükleme kapasitesine göre değişebilir) \\
\hline
\end{tabular}

Çalışmada deney numuneleri iki gruba ayrılmıştır. Her iki gruptaki numuneler, geleneksel 1sıl işleme tabi tutularak 60-62 HRC sertliğine çıkarılmıştır. Birinci gruba uygulanan işlem sadece geleneksel 1sıl işlem iken, ikinci gruptaki numuneler, geleneksel 1sıl işlemden sonra sı̆̆ kriyojenik işlem ($80{ }^{\circ} \mathrm{C}$ 'de 18 saat) ve akabinde temperleme işlemine tabi tutulmuştur. Temperleme işlemi 2 saat süre ile $200{ }^{\circ} \mathrm{C}$ 'de yapılmıştır. Deney numunelerinin sınıflandırılması ve uygulanan isıl işlemler Tablo 3 'te verilmiştir.
Mikroyapı çalışmalarında kullanılmak üzere 10 $\mathrm{mm}$ çapında ve yüksekliğinde numuneler hazırlanmıştır. Bu numuneler geleneksel ısıl işlem ve sı ̆ kriyojenik işlemden sonra sırasıyla 120, 240, 600, 800 ve 1200 grit $\mathrm{SiC}$ aşındırıcılar ile zımparalanmıştır. Daha sonra Nital solüsyonu ile dağlama işlemine tabi tutulmuş ve optik mikroskop altında incelenmiştir.

Tablo 3. Geleneksel 1sıl işlem ve derin kriyojenik işlem uygulaması (Application of conventional heat treatment and deep

\begin{tabular}{ccc}
$\begin{array}{c}\text { Numune } \\
\text { Grubu }\end{array}$ & $\begin{array}{c}\text { Numune } \\
\text { Ad1 }\end{array}$ & cryogenic process) \\
\hline 1 & CHT & Uygulanacak Isıl İşlem \\
2 & SCT-24 & Geleneksel Isıl İşlem + Derin kriyojenil isıl işlem \\
\hline
\end{tabular}

Deney numuneleri üzerine uygulanan işlemlerin etkisini görebilmek amacıyla mikro sertlik ve makro sertlik deneyleri yapılmıştır. Makro sertlik ölçümleri Time TH 300 marka makro sertlik cihazı ile Rockwell C (HRC) sertlik ölçme metodu kullanılarak gerçekleştirilmiştir. Ölçümlerin doğruluk kontrolü için aynı numune üzerinde 5 farklı bölgeden sertlik değeri alınmış olup bu değerlerin ortalamaları alınarak kullanılmıştır. Mikro sertlik ölçümleri Metkon marka DUROLINE-M model sertlik cihazı kullanılarak mikro sertlik ölçme işlemi gerçekleştirilmiştir. XRD yöntemi ile malzemelerdeki kalıntı östenit hacim oranları ölçülerek, numuneler üzerindeki işlem farklılıklarına göre numuneler arasındaki farkın tespit edilmesi amacıyla, kalıntı östenit ölçümleri Atılım Üniversitesi

Metal Şekillendirme Mükemmeliyet Merkezi'nde yapılmıştır. Kalıntı östenit değerlerine kriyojenik işlem uygulamasının doğrudan etkilenmesi sebebiyle malzemenin kalıntı östenit değerlerinin ölçülmesi önem teşkil etmektedir [20]. Kalıntı östenit testi SEIFERT Analytical X-ray MZ VI marka X-ışını difraksiyon cihazında gerçekleştirilmiş olup cihaz, Şekil 4'te verilmiştir. Çalışmada kalıntı östenit hacim oranının belirlenmesinde kullanılan ölçüm parametreleri Tablo 4'te verilmiştir. 
Tablo 4. Kalıntı östenit ölçüm parametreleri (Residual austenite

\begin{tabular}{|c|c|}
\hline \multicolumn{2}{|c|}{ measurement parameters) } \\
\hline Odak noktası & $\varnothing 1 \mathrm{~mm} \times 135 \mathrm{~mm}$ kolimatör \\
\hline Hassas konum dedektörü & Aktif aralık: $16,4^{\circ}$ \\
\hline Anot malzemesi & $\mathrm{Cr}$ \\
\hline Filtre & Vanadyum \\
\hline Tüp voltaj1 & $30 \mathrm{kV}$ \\
\hline Tüp akımı & $55 \mathrm{~mA}$ \\
\hline \multirow{3}{*}{ Tarama 1} & Aralık: $62^{\circ}-74^{\circ}$ \\
\hline & Çözünürlük: $0,05^{\circ}$ \\
\hline & Ölçüm süresi: 2 dakika 24 saniye \\
\hline \multirow{3}{*}{ Tarama 2} & Aralik: $74^{\circ}-84^{\circ}$ \\
\hline & Çözünürlük: $0,05^{\circ}$ \\
\hline & Ölçüm süresi: 1 dakika 30 saniye \\
\hline \multirow{3}{*}{ Tarama 3} & Aralık: $101^{\circ}-110^{\circ}$ \\
\hline & Çözünürlük: $0,05^{\circ}$ \\
\hline & Ölçüm süresi: 1 dakika 30 saniye \\
\hline \multirow{3}{*}{ Tarama 4} & Aralık: $121^{\circ}-137^{\circ}$ \\
\hline & Çözünürlük: $0,05^{\circ}$ \\
\hline & Ölçüm süresi: 3 dakika \\
\hline
\end{tabular}

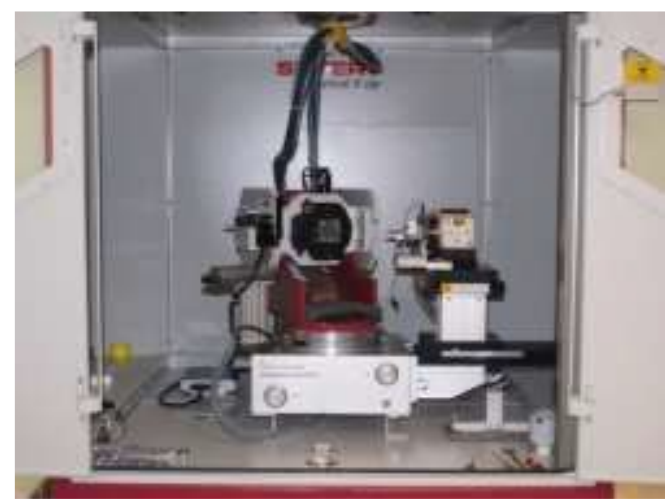

Şekil 4. X-ışını difraksiyon cihazı (X-Ray diffraction device)

\section{BULGULAR VE TARTIŞMA (RESULTS AND DISCUSSION)}

Kalıntı östenit kriyojenik işlem uygulanmış malzemelerin değişim özelliklerini açıklayan önemli metalürjik yöntemlerden biridir. Kalıntı östenitin martenzite dönüşümü malzemelerin mekanik özellikleri üzerinde büyük etkiye sahiptir. Yumuşak bir faz olan kalıntı östenitin sert bir faz olan martenzit fazı ile beraber yapıda bulunması istenmeyen bir durumdur. Bunun nedeni kalıntı östenit sertlik başta olmaz üzere, mekanik özelliklerin tamamını olumsuz olarak etkilemektedir. $\mathrm{Bu}$ sebeple kalıntı östenitin martenzite dönüşümü gereklidir. Şekil 5'te Sleipner soğuk iş takım çeliğine uygulanan sı̆̆ kriyojenik işleminin ardından yapıdaki kalıntı östenit hacim oranlarındaki değişim verilmiştir.

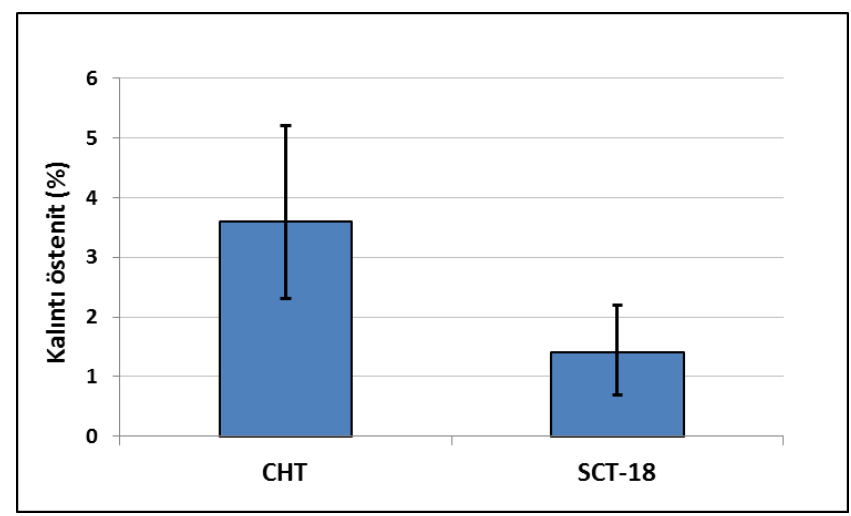

Şekil 5. Kriyojenik işlemin kalıntı östenit hacim oranına etkisi (Effect of cryogenic treatment on residual austenite volume ratio)

Şekil 5'te görülen CHT numunesi için kalıntı östenit hacim oranı \% 3,6 olarak bulunmuştur. SCT numune üzerinde kalıntı östenit oranı \% 1,4 olarak bulunmuştur. SCT-18 numunesi CHT numunesi ile karşılaştırıldığında kalıntı östenit hacim oranındaki azalma yaklaşık olarak \% 61 'dir. $\mathrm{Bu}$ sonuç, geleneksel işleminin uygulanmasının ardından yapılan kriyojenik işlem uygulamasının istenmeyen faz olan yumuşak kalıntı östenit fazının, daha sert bir faz olan martenzit fazına dönüştürmede büyük başarı sağladığını göstermektedir. $\mathrm{Bu}$ durum literatür araştırmalarıyla da paralellik göstermektedir.

Yüksek alaşım ve karbon içeren takım çelikleri üzerinde uygulanan kriyojenik işlem ile ardından yapılan temperleme işleminin yapıdaki kalıntı östenitin martenzit fazına dönüştüğü belirtilmiştir [21]. Kriyojenik işlem uygulanmasının kalıntı östenit hacim oranında \% 30-40 oranında düşüş sağladığı tespit edilmiştir [22]. 
Sertlik ölçümleri, mekanik özelliklerin incelenmesinde diğer yöntemlere göre daha çok tercih edilmektedir. Deneyin basit ve diğer yöntemlere göre malzeme üzerinde daha az tahribat oluşturması kullanım oranını artırmaktadır. Çelik malzemelerde sertlik çekme mukavemeti ile doğru orantılıdır. Dolayısıyla malzemenin sertlik değerinin bilinmesi diğer mekanik özellikleri hakkında da bir değerlendirme yapılabilmesini sağlamaktadır.
Sleipner soğuk iş takım çeliği numunelerinin tümüne geleneksel isıl işlem uygulanmış (CHT), ardından 18 saat süreyle $-80{ }^{\circ} \mathrm{C}$ ' de sı ̆ kriyojenik isıl işlem uygulanmış (SCT-18) olup 2 farklı gruba ayrılmıştır. Sertlik ölçümleri numune üzerindeki 5 farklı bölgeden yapılarak, bu değerlerin ortalaması alınmıştır. Makro sertlik ölçüm sonuçları Şekil 6'da verilmiştir.

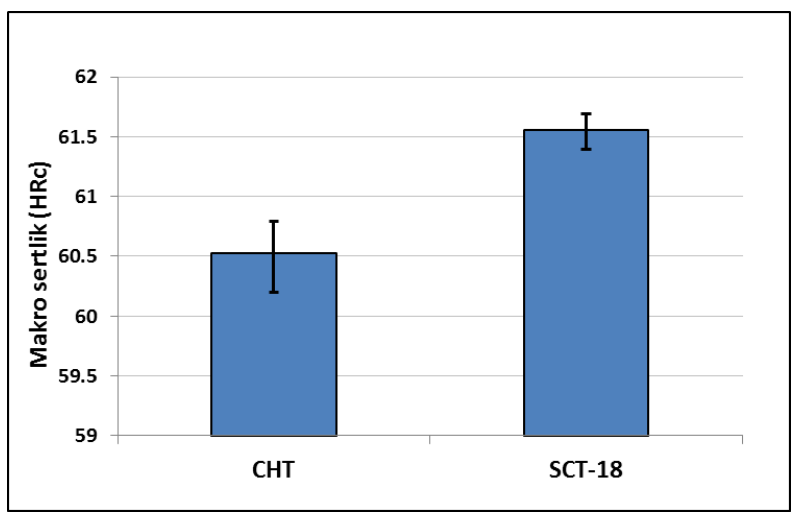

Şekil 6. Kriyojenik işlemin makro sertlik üzerindeki etkisi (Effect of cryogenic process on macro hardness)

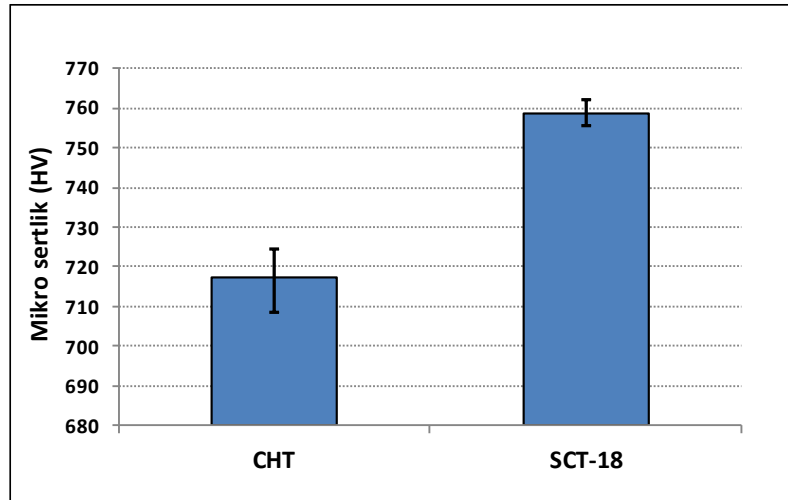

Şekil 7. Kriyojenik işlemin mikro sertlik üzerindeki etkisi (Effect of cryogenic treatment on micro hardness)

Yapılan sertlik test sonuçları incelendiğinde, geleneksel ısıl işlem sonrasında uygulanan kriyojenik işlem ve akabindeki temperleme işleminin makro sertlikte artışa neden olduğu tespit edilmiştir. CHT numunesinin sertliği 60,2 HRC olarak tespit edilmiştir. SCT-18 numunesinin sertlik değeri ise 61,4 HRC olarak tespit edilmiştir. Kriyojenik işlem uygulamasının makro sertlik yönünden SCT-18 numunesi üzerinde \% 2 civarında bir iyileşmeye sebep olduğu görülmüştür. Bu durum malzemenin yapısında istenmeyen kalıntı östenit fazının, sert faz olan martenzite dönüşmesi ile ilişkilendirilmiştir. $\mathrm{Bu}$ durum için literatüre bakıldığında, araştırma malzemesi olarak AISI 52100 rulman çeliğinin kullanıldığ kalıntı östenit fazının kriyojenik işlem uygulanması sonucunda, bu fazın daha sert bir faz olarak bilinen martenzit fazına dönüştüğü gözlemlenmiştir [23].

Başka bir çalışmada deneysel sonuçlara göre, kriyojenik işlem uygulanan malzemede sertlikte \% 22'lik bir oranda artış olduğu tespit edilmiştir [24]. Şekil 7'de elde edilen mikro sertlik değerlerinin değişim durumu gösterilmiştir. Mikro sertlik sonuçlarına bakıldığında CHT numunesinde 708,7 HV sertlik tespit edilmiştir. SCT-18 numunesinin sertlik değeri ise 755,6 HV olarak tespit edilmiştir. Kriyojenik işlem uygulamasını mikro sertlik yönünden SCT-18 numunesi üzerinde \% 7 civarında bir sertlik artışına neden olmuştur. Bu durum kalıntı östenitin, sert faz martenzite dönüşmesine atfedilmiştir. 
Kriyojenik işlemin farklı bekleme sürelerinde uygulandığında sertlik yönünden artışa neden olduğu yönünde yapılan deneysel çalışmada, hem makro hem mikro sertlik incelemeleri sonucunda 1.2080 soğuk iş takım çeliğinde sertlik artışları görülmüştür [25]. AISI D2 malzemesi üzerinde uygulanan farklı bekletme sürelerinde kriyojenik işlem ile sertlik değerlerinde artış olduğu gözlemlenmiştir [26.]

Yapılan sertlik deneyleri incelendiğinde kriyojenik işlem uygulamasının ve akabinde uygulanan temperleme işleminin mikro ve makro sertlik yönünden malzemede olumlu sonuçlar sağladığı görülmüştür. Literatürde yapılan araştırma sonuçlarıyla da benzerlik göstermiştir. Makro ve mikro sertlik değerlerinde yaşanan bu durum kriyojenik işlemin en önemli etkisi olan yumuşak faz kalıntı östenitin, sert faz olan martenzite dönüşmesi ve karbür çökelmesi sebebiyle sertlikte artışa sebep olduğuna atfedilmiştir. 3.3. Mikroyapı Analizi Sonuçları Sleipner soğuk iş takım çeliği üzerinde uygulanan sı̆̆ kriyojenik işlemin etkilerinin belirlenebilmesi için numunelerin mikroyapı görüntüleri alınmıştır. Yapılan mikroyapı analizlerinin sebebi uygulanan kriyojenik işlemden sonra mikro sertlik, makro sertlik, gibi mekanik özelliklerde oluşan artış değerlerinin açıklayabilmektir.

Çeliklere uygulanan geleneksel 1sıl işlemden sonra kriyojenik işlemin uygulanması durumunda yapıdaki kalıntı östenitin martenzite dönüştüğü bilinmektedir. Kriyojenik işlem uygulanmış malzemelerin yapıları gözlemlendiğinde yapılarının daha yoğun ve düzenli olduğu görülmüştür. Kriyojenik işlemin etkilerinden bir başkası ise yapıda meydana gelen martenzitin ayrışması ve karbür çökelmesidir [27].

$\mathrm{Bu}$ çalışmada araştırma malzemesi olarak kullanılan Sleipner soğuk iş takım çeliğinin CHT numunesinin mikroyapısı incelendiğinde östenit ve martenzit fazları görülmüştür. Uygulanan kriyojenik işlemden sonra SCT-18 numunesi incelendiğinde mikroyapıdaki görüntüler Şekil 8'deki gibi değişiklik göstermiştir.

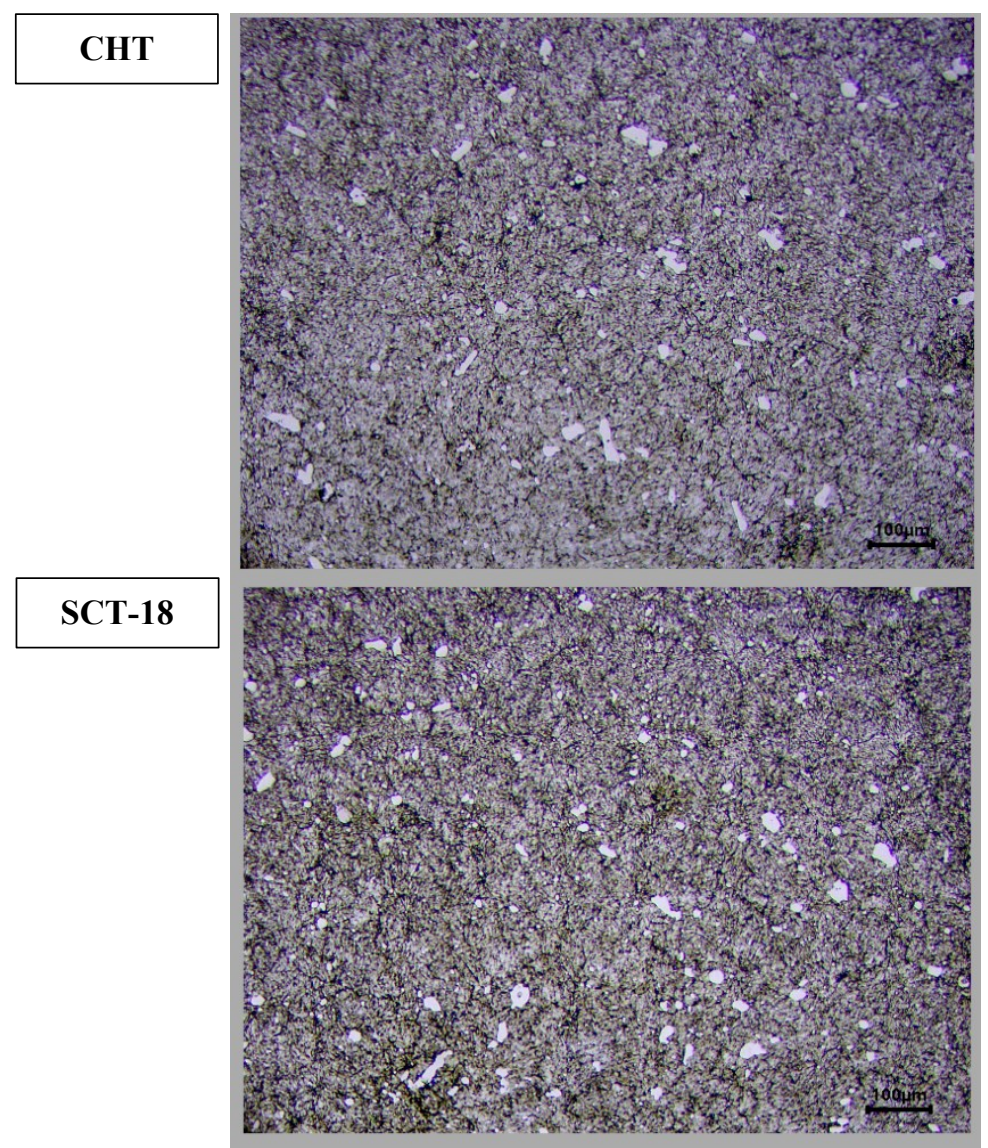

Şekil 8. Sleipner soğuk iş takım çeliği mikro yapı görüntüleri (Micro structure images of Sleipner cold work tool steel)

CHT numuneleri uniform birincil olmayan karbür dağılımı göstermişken, SCT-18 numunesinde ise mikroyapıdaki karbürlerin daha homojen bir dağılım gösterdiği, daha ince karbür çökelmesinin gerçekleştiği görülmektedir. Numuneler üzerinde kriyojenik işlem uygulanmış ve ardından temperleme 
işlemi gerçekleştirilmiş çalışmada, mikroyapı incelemelerinde çok daha ince partikül dağılımı görülmüştür [7]. Mikroyap1 üzerine yapılan araştırmalara bakıldığında, farklı bekletme sürelerinde uygulanan kriyojenik işlemin karbür yüzdesinde artışa neden olduğu tespit edilmiştir [25]. Genel bir değerlendirmeyle mikroyap1 görüntüleri incelendiğinde, uygulanan sığ kriyojenik işlemin çelik üzerinde daha homojen bir yapı sağladığı görülmüştür. Kriyojenik işlem ardından yapılan temperlemenin ise ikinci ince karbürlerin çökelmesinde etkili olduğu görülmüştür. Bu sonuçlar literatürde yapılan çalışmalar ile benzerlik göstermektedir.

\section{SONUÇLAR ( CONCLUSIONS)}

Bu çalışmada, Sleipner soğuk iş takım çeliğinin iki farklı varyantı CHT ve SCT-18 numuneleri oluşturularak kalıntı östenit hacim oranları, makro ve mikro sertlikleri, mikroyapıları üzerinde oluşan farklılıklar araştırılmıştır. Kalıntı östenit ölçümleri XRD yöntemiyle incelenmiş, mekanik özellikler makro ve mikro sertlik yönünden araştırılmış olup, mikroyapı değişiklikleri ise SEM analizleri ile incelenmiştir. Elde edilen sonuçlar aşağıda maddeler halinde verilmiştir.

- Kalıntı östenit hacim oranı analizi sonunca, SCT-18 numunelerinde yaklaşık olarak \% 61'lik bir iyileşme görülmüştür.

- Metalografik sonuçlara göre kalıntı östenit ve mikroyapılar incelendiğinde SCT-18 numunelerinde daha homojen bir mikro yap1 ve daha iyi bir ikincil karbür çökelmesi görülmüştür.

- CHT ve SCT numunelerinin mikroyapıları incelendiğinde SCT numunelerine ait SEM görüntülerinde östenit fazının martenzite dönüştürülmesinde başarılı bir sonuç elde edilmiştir.

- SCT-18 numunesindeki martenzit fazı miktarı CHT numunesine görülen martenzit fazından daha fazla olduğu görülmüștür. $\mathrm{Bu}$ durum kriyojenik işlemin kalıntı östenit miktarının martezite dönüştürülmesinde başarılı bir sonuç elde edilmiștir.

- Kriyojenik işlem görmüş SCT-18 numuneleri kriyojenik işlemin başarılı uygulanması sonucunda elde edilen yüksek martenzit fazına bağlı olarak mekanik özellikler yönünden daha başarılı sonuçlar vermiştir. Sertlik deneyleri ile bu durum desteklenmektedir.

- Makro sertlik sonuçlarına göre CHT numunelerinde 60,2 HRC, SCT-18 numunelerinde 61,4 HRC sertlik değeri ölçülmüştür. Mikro sertlik sonuçlarına göre CHT numunelerinde 708,7 HV, SCT-18 numunelerinde 755,6 HV sertlik değeri ölçülmüştür. SCT-18 numunelerinde makro sertlik ve mikro sertlikte sırasıyla yaklaşık olarak $\% \quad 2$ ve $\% \quad 7$ oranında bir artış görülmüştür.

$\mathrm{Bu}$ çalışmada yapılan araştırmalar sonucunda Sleipner soğuk iş takım çeliğine uygulanan sı̆̆ kriyojenik işlem ile kalıntı östenit oranları, sertlik ve mikroyapıda olumlu iyileştirmeler görülmüştür. Kriyojenik işlem üzerine yapılacak yeni çalışmalarda, Sleipner soğuk iş takım çeliği için farklı bekleme süreleri ve sıcaklıklarda sı ̆̆ ve derin kriyojenik işlemin etkileri araştırılabilir.

\section{TEŞEKKÜR (ACKNOWLEDGEMENT)}

$\mathrm{Bu}$ çalışma Düzce Üniversitesi Bilimsel Araştırma Projeleri (DÜBAP) Koordinatörlüğü tarafindan 2019.07.04.1046 no'lu proje ile desteklenmiștir. Kuruma desteklerinden ötürü teşekkür ederiz.

\section{ÇIKAR TARTIŞMASI BİLDİRIMI (CONFLICT OF INTEREST STATEMENT)}

Yazarlar tarafından herhangi bir çıkar çatışması bildirilmemiştir.

\section{KAYNAKLAR (REFERENCES)}

[1] N. Altan Özbek and E. Saraç, "Temperleme isıl işlem sicaklıklarının AISI 1020 ve AISI 1040 karbon çeliklerin mekanik özellikleri üzerine etkileri," Gazi Mühendislik Bilim. Derg., vol. 7, no. 1, pp. 17-25, 2021 .

[2] E. Demir and İ. Toktaş, "AISI D2 çeliğine uygulanan farklı bekletme sürelerindeki derin kriyojenik işlemin yüzey pürüzlülüğüne etkisinin incelenmesi," in 2. International Symposium on Innovative Technologies in Engineering and Science, Istanbul, 2014, pp. 2038-2049.

[3] H. Gökçe and M. Yavuz, "Ticari saflıktaki molibden malzemesine HSS kılavuzla vida açma işleminde kesme hızının etkisi," Gazi Mühendislik Bilim. Derg., vol. 5, no. 3, pp. 237-243, 2019.

[4] G. Höke, İ. Şahin, H. Çinici, and T. Fındık, "Kriyojenik işlemin SAE 4140 çeliğinin mekanik özellikleri üzerine etkisi," Selçuk Üniversitesi SelçukTeknik Dergisi, vol. 13, no. 2, pp. 25-37, 2014. 
[5] D. Akgümüş Gök and V. Öztürk, "Kriyojenik işlemin Vanadis 8 çeliğinin mekanik özellikleri ve mikroyapısı üzerindeki etkisi," Uluslararası Doğu Anadolu Fen Mühendislik ve Tasarım Derg., vol. 2, no. 1, pp. 22-32, 2020.

[6] A. Çiçek, E. Ekici, İ. Uygur, S. Akıncıoğlu, and T. Kıvak, "AISI D2 soğuk iş takım çeliğinin delinmesinde derin kriyojenik işlemin takım ömrü üzerindeki etkilerinin araştırılması," Süleyman Demirel Üniversitesi Uluslararast Teknol. Bilim. Derg., vol. 4, no. 1, pp. 1-9, 2012.

[7] M. Özer, “AISI H13 takım çeliğine uygulanan derin kriyojenik işlem ve temperleme 1sıl işleminin mikroyap1, sertlik ve darbe enerjisine etkisi," Gazi Üniversitesi Fen Bilim. Derg. Part C Tasarım ve Teknol., vol. 7, no. 3, pp. 688-699, 2019.

[8] İ. D. K. Demir and İ. Uygur, “AZ63 magnezyum alaşımının korozyon direncine kriyojenik işlemin etkisi," Ileri Teknol. Bilim. Derg., vol. 8, no. 2, pp. 17-27, 2019.

[9] S. S. Gill, R. Singh, H. Singh, and J. Singh, "Wear behaviour of cryogenically treated tungsten carbide inserts under dry and wet turning conditions," Int. J. Mach. Tools Manuf., vol. 49, no. 3-4, pp. 256-260, 2009.

[10] P. Paulin, "Frozen Gears," Gear Technol., pp. 26-29, 1993.

[11] P. Baldissera and C. Delprete, "Effects of deep cryogenic treatment on static mechanical properties of $18 \mathrm{NiCrMo} 5$ carburized steel," Mater. Des., vol. 30, no. 5, pp. 1435-1440, 2009, [Online]. Available: https://dx.doi.org/10.1016/j.matdes.2008.08.015

[12] A. Akhbarizadeh, A. Shafyei, and M. A. Golozar, "Effects of cryogenic treatment on wear behavior of D6 tool steel," Mater. Des., vol. 30, no. 8, pp. 3259-3264, 2009, [Online]. Available: https://dx.doi.org/10.1016/j.matdes.2008.11.016

[13] A. Bensely, A. Prabhakaran, D. Mohan Lal, and G. Nagarajan, "Enhancing the wear resistance of case carburized steel (En 353) by cryogenic treatment," Cryogenics (Guildf)., vol. 45, no. 12, pp. 747-754, 2005.

[14] J. Y. Huang, Y. T. Zhu, X. Z. Liao, I. J. Beyerlein, M. A. Bourke, and T. E. Mitchell, "Microstructure of cryogenic treated M2 tool steel," Mater. Sci. Eng. A, vol. 339, no. 1-2, pp. 241-244,
2003. doi: https://dx.doi.org/10.1016/ S0921-5093(02)00165-X

[15] A. A. Khan and M. I. Ahmed, "Improving tool life using cryogenic cooling," J. Mater. Process. Technol., vol. 196, no. 1-3, pp. 149-154, 2008.

[16] F. K. Arslan, I. Altinsoy, A. Hatman, M. Ipek, S. Zeytin, and C. Bindal, "Characterization of cryogenic heat treated Vanadis 4 PM cold work tool steel," Vacuum, vol. 86, no. 4, pp. 370-373, 2011.

[17] K. Amini, A. Akhbarizadeh, and S. Javadpour, "Investigating the effect of the quench environment on the final microstructure and wear behavior of 1.2080 tool steel after deep cryogenic heat treatment," Mater. Des., vol. 45, pp. 316-322, 2013, doi: https://dx.doi.org/10.1016/j.matdes.2012.08.006

[18] R. Sola, R. Giovanardi, G. Parigi, and P. Veronesi, "A novel method for fracture toughness evaluation of tool steels with post-tempering cryogenic treatment," Metals (Basel)., vol. 7, no. 3, pp. 1-9, 2017.

[19] K. Amini, S. Nategh, and A. Shafyei, "Influence of different cryotreatments on tribological behavior of 80 CrMo12 5 cold work tool steel," Mater. Des., vol. 31, no. 10, pp. 4666-4675, 2010. doi: https://dx.doi.org/10.1016/j.matdes.2010.05.028

[20] F. Kara, “AISI 52100 çeliğinin yorulma ömrü ve taşlanabilirliğine kriyojenik işlem parametrelerinin etkilerinin araştırılması," Doktora Tezi, Karabük Üniversitesi, Fen Bilimleri Enstitüsü, Karabük, 2014.

[21] H. Li, W. Tong, J. Cui, H. Zhang, L. Chen, and L. Zuo, "The influence of deep cryogenic treatment on the properties of high-vanadium alloy steel," Mater. Sci. Eng. A, vol. 662, pp. 356-362, 2016. doi: https://dx.doi.org/10.1016/j.msea.2016.03.039

[22] H. S. Yang, W. Jun, S. Bao-Luo, L. Hao-Huai, G. Sheng-Ji, and H. Si-Jiu, "Effect of cryogenic treatment on the matrix structure and abrasion resistance of white cast iron subjected to destabilization treatment," Wear, vol. 261, no. 10, pp. 1150-1154, 2006. doi: https://dx.doi.org/10.1016/j.wear.2006.03.021

[23] A. Akhbarizadeh, S. Javadpour, K. Amini, and A. H. Yaghtin, "Investigating the effect of ball milling during the deep cryogenic heat treatment of the 1.2080 tool steel," Vacuum, vol. 90, no. 1, pp. 70-74, 2013. 
[24] J. Yi et al., "Enhanced toughness and hardness at cryogenic temperatures of silicon carbide sintered by SPS," Mater. Sci. Eng. A, vol. 569, pp. 13-17, 2013.

doi: https://dx.doi.org/10.1016/j.msea.2013.01.053

[25] K. Amini, A. Akhbarizadeh, and S. Javadpour, "Investigating the effect of holding duration on the microstructure of 1.2080 tool steel during the deep cryogenic heat treatment," Vacuum, vol. 86, no. 10, pp. 1534-1540, 2012.

doi: https://dx.doi.org/10.1016/j.vacuum.2012.02.013

[26] D. Das, A. K. Dutta, and K. K. Ray, "Influence of varied cryotreatment on the wear behavior of AISI D2 steel," Wear, vol. 266, no. 1-2, pp. 297-309, 2009.

doi: https://dx.doi.org/10.1016/j.wear.2008.07.001

[27] Y. Dong, X. Lin, and H. Xiao, "Deep cryogenic treatment of high-speed steel and its mechanism," Heat Treat. Met., vol. 25, no. 3, pp. 55-59, 1998. 